The Numbers We Need: Review of Shifting Contexts, Stable Core: Advancing Quantitative Literacy in Higher Education, edited by Luke Tunstall, Gizem Karaali, and Victor Piercey (2019)

John Maclnnes

University of Edinburgh, john.macinnes@ed.ac.uk

Follow this and additional works at: https://digitalcommons.usf.edu/numeracy

Part of the Curriculum and Instruction Commons, Higher Education Commons, Science and Mathematics Education Commons, and the Social and Behavioral Sciences Commons

Recommended Citation

Maclnnes, John. "The Numbers We Need: Review of Shifting Contexts, Stable Core: Advancing Quantitative Literacy in Higher Education, edited by Luke Tunstall, Gizem Karaali, and Victor Piercey (2019)." Numeracy 12, Iss. 2 (2019): Article 15. DOI: https://doi.org/10.5038/1936-4660.12.2.15 


\title{
The Numbers We Need: Review of Shifting Contexts, Stable Core: Advancing Quantitative Literacy in Higher Education, edited by Luke Tunstall, Gizem Karaali, and Victor Piercey (2019)
}

\author{
Abstract \\ Luke Tunstall, Gizem Karaali, and Victor Piercey, eds. 2019. Shifting Contexts, Stable Core: Advancing \\ Quantitative Literacy in Higher Education. Math Notes 88. (Mathematics Association of America, MAA \\ Press). Print ISBN 978-0-88385-198-2. Electronic ISBN 978-1-61444-324-7.
}

\begin{abstract}
Mine is a rather UK-centric view. The ability to understand numbers is increasingly vital for citizenship in a world where almost every argument, no matter how bogus, comes with numbers attached. Maths and stats, however, are too important to leave to the mathematicians and statisticians alone. There are as many varieties of application as there are disciplines and interests. Maths faculty are not there to be polymaths. The best solution to this problem is as much interaction as possible between maths and stats and 'applied' disciplines. I don't know about the US, but in the UK such interdisciplinarity is lauded in principle but crushed in practice by the target culture sweeping across education. In addition, I found many items on which to agree. In sum, I can report that Shifting Contexts is full of useful experiences and experiments for us to consider. Moreover, both sides of the Atlantic would benefit from a closer relationship and fuller discussion of what both of us are trying, and sometimes succeeding, to do
\end{abstract}

\section{Keywords}

numeracy, quantitative literacy, maths education, MAA Notes

\section{Creative Commons License}

\section{(c) (7) (8)}

This work is licensed under a Creative Commons Attribution-Noncommercial 4.0 License

\section{Cover Page Footnote}

John Maclnnes is a Vice President of the Royal Statistical Society and chairs its Professional Affairs Committee, Strategic Advisor on Quantitative Skills to the British Academy and Professor of Sociology at the University of Edinburgh. His 2009 report to the Economic and Social Research Council led to the development of the Q-Step programme in the UK. He sits on the advisory board of Maths in Education and Industry, and recently completed a project on Statistics Anxiety for the ESRC National Centre for Research Methods. 
'Mathematicians have very little to do with numbers' - Halmos $(1968,376)$

When the copy of Shifting Contexts, Stable Core (henceforth, Shifting Contexts) arrived on my desk I was not sure what to expect. I had heard about Mathematics and Democracy and read a few pieces in Numeracy, but, I suspect like many people in the business of promoting the value of numbers, had been too busy doing it to spend enough time reflecting upon it, and knew far more about the UK scene (and universities and statistics) than elsewhere. Over the last decade, I've been trying to raise the profile of statistics and quantitative evidence within UK university social science. In the era of 'Big Data' this effort should be pushing at an open door, but it has often felt more like banging one's head against a closed one. A string of reports, projects and enquiries stretching back to 1946 either bemoan the numerical weakness of UK social science or set out (unsuccessfully) to improve it. There is a broader problem of numeracy teaching from primary school onwards, a challenge that the Nuffield Foundation, ${ }^{1}$ Maths in Education and Industry, ${ }^{2}$ National Numeracy ${ }^{3}$ and others in the UK do their best to confront.

I found something familiar in every chapter in Shifting Contexts, although I'm sure the details of the landscape differ. The issues of curriculum content, how to engage students on their own terms, how to make the links between maths and ethics, social justice or politics, how to cope with diverse or crosscutting institutional goals and structures, how to use assessment to support learning rather than substitute for it, how to step back and evaluate what we do, and how to do all that without transforming enthusiasm into exhaustion are all questions we face here too. That encouraged me to try to identify some core insights that such familiarity might be evidence of. Here they are, with apologies for a rather UK-centric view, and, of course, a disclaimer that it may all be merely my wishful thinking.

The ability to understand numbers is increasingly vital for citizenship in a world where almost every argument, no matter how bogus, comes with numbers attached. People competent with numbers are more likely to recognise their abuse by others. We know this. Most of our students know it too. However we also know that (1) this insight is not motivation enough for most people to get on with the math; (2) there is a lot more to politics than arithmetic; and (3) demonstrating the relevance and power of quantitative reasoning is difficult. The world is a messy place. Compelling, accessible examples of powerful quantitative reasoning do not grow on trees.

\footnotetext{
${ }^{1}$ https://www.nuffieldfoundation.org/ (accessed June 5, 2019)

2 http://mei.org.uk/ (accessed June 5, 2019)

3 https://www.nationalnumeracy.org.uk/ (accessed June 5, 2019)
} 
Maths and stats are too important to leave to the mathematicians and statisticians. One could not say this about Chemistry, Astronomy or English Literature; at least not in the same way. Everyone needs maths and stats, but the maths and stats they need are seldom what interests the mathematicians or statisticians. There is nothing wrong with this, but it creates two challenges. The first challenge is how best to manage the division of intellectual labour involved in teaching 'applied' maths and stats, including how to delimit and define it. I see that it goes under as many different names in the US as in the UK: applied, functional and expressive maths, QR, QL, quantitative / numerical / statistical / data literacy, and maths 'for life' (which I guess is the inverse of actuarial maths). Much of Shifting Contexts about this definition, for good reasons.

Excellent mathematicians or statisticians often cannot teach the maths and stats we need because they cannot imagine, let alone relate to, just how innumerate most students are (at any level of schooling). 'Application' is not, and cannot be, their responsibility. There are as many varieties of application as there are disciplines and interests. Maths faculty are not there to be polymaths. This usually means that, with some wonderful exceptions, those promoting numeracy or statistical literacy do not themselves come from within the maths community. They are usually subject specialists with an interest in maths, not mathematicians or statisticians with an interest in a substantive area.

That need not be a problem but it carries some risk of the consolidation of bad habits, poor understanding or poor teaching within disciplinary silos. At its worst it leaves the maths badly done or just ignored: squeezed out of the curriculum by substantive issues. Witness the current debate about the use of $p$-values, significance thresholds and the replication crisis in some areas of science, or the alarmingly bad interpretation of statistics by medical or legal professionals. The best solution to this is as much interaction as possible between maths and stats and 'applied' disciplines. I don't know about the US, but in the UK such interdisciplinarity is lauded in principle but crushed in practice by the target culture sweeping across education. It is an exaggeration, but not a gross one, to describe UK school maths as application and relevance free. Bolker (p. 200) describes this maths 'conspiracy':

The teacher promises that the questions in the final will be just like those in the book, with different numbers. When the student answers they can pretend they learned something; the teacher can pretend to have taught something.

Such contentless maths has never been a good idea, but given its focus on calculation it seems less relevant than ever in a world of computers. In the UK this syndrome is called 'teaching to the test' and is a kind of stealth bomber of 
numeracy. It produces students whose only skill is to match a formula to specific cues in question wording. It is useless and pointless.

This division of labour will be broken by data. Because of the rise of the data economy, the Big New Thing in education is data skills. Who will teach them? Maths teachers don't do data. It requires application (data does tend to be about something) and probabilistic rather than deductive reasoning. Other teachers don't feel comfortable with the maths. Something will have to give, but as yet it is not clear what.

If the distinction between maths and its application is one challenge, the second one is a bit of an elephant in the room. Innumeracy is widespread because numbers are difficult. That is why we have initiatives in numerical, quantitative, statistical, digital or data literacy, but not literacy literacy. Communication, expression, description, and logical argument are just as vital for civics. Not everyone is a budding Shakespeare, but the vast majority of students at any age can argue, debate and persuade without having to stop and think about it. Not so numbers. They need effort. Effort that not everyone is willing to invest. I suspect we know less about this challenge than the first, and we could do with understanding it better, not least because of the paradox that we have had machines to take care of most of this effort for half a century now. I suspect we don't use them wisely. The chapter by Gaze on teaching using spreadsheets is a good place to start thinking about this.

I think it is because of these two challenges that a lot of our work is about maximising the short-term return to students for investing in that effort. We try to show them that numbers are worth it. A temptation to avoid is insisting too much that numbers are simple, or easier than they in fact are, or that their relevance is obvious. There is no easy, quick marriage between maths and relevance. It usually needs mechanics (some skills with excel or other software), substantive knowledge (which is rarely shared by all members of a class and has to be mastered if it is to be a vehicle for the maths) and realism about what can be achieved, which often collides with a longer list of the maths skills we would like students to gain.

Shifting Contexts is full of useful experiences and experiments to consider. Among the insights it reinforced for me? Fractions. One number divided by another is one of the simplest components of maths, but a foundation for so much else. Students who don't need to stop and think through a fraction from first principles have their minds free to use them as a vehicle for understanding, rather than facing another chunk of cognitive load. Pictures. Our brains may not be wired for numbers but they can do graphics. So can computers. We ought to do better at exploiting this connexion. Time. There is so much to do + curriculum space is always at a premium $=$ going too fast and losing the 
students. This is compounded by the need to challenge the best students without deserting the slower ones. Modesty. Let's teach the world to count first, that is a contribution to challenging 'asymmetries of power' and even 'individualist perspectives'. Numbers are inherently subversive because they are plural. That may be a surer route to progress than finding the secret to tackling everything at once.

I hope Shifting Contexts reaches a significant British audience. Both sides of the Atlantic would benefit from a closer relationship and fuller discussion of what we are trying, and sometimes succeeding, to do.

\section{Reference}

P. R. Halmos. 1968. "Mathematics as a Creative Art." American Scientist 56(4): 375-389. 